\title{
Phytochemical analysis and Invitro antioxidant activity of silver nanoparticle synthesized Crateva religiosa bark extract
}

\section{Charu Prabha. V ${ }^{1 *}$, Dr. K. Chandra Prabha ${ }^{2}$, Dr.S.Vijayakumar ${ }^{3}$}

M.Phil Scholar ${ }^{1}$,Associate Professor ${ }^{2}$,Department of Biochemistry,Navarasam Arts and Science College for Women,Arachalur,Erode-638101,Director and Researcher ${ }^{3}$,VJ Biotech,Coimbatore.

\begin{abstract}
The aim of the study is to determine the phytochemical analysis and antioxidant activity of silver nanoparticle synthesized aqueous bark extract of Crateva religiosa. The aqueous extract of Crateva religiosa barks are prepared by maceration method. The qualitative phytochemical and quantitative phytochemical analysis was carried out using standard procedures. Silver nanoparticle was synthesized for the aqueous extract. Then the antioxidant activity was determined by DPPH scavenging activity and FRAP assay. The qualitative phytochemical analysis shows the presence of alkaloids, flavonoids, phenols, tannins, saponins. Total phenol content of bark extract was found to be $1.423 \mathrm{mg} / \mathrm{g}$. Total flavonoid content was found to be $1.6 \mathrm{mg} / \mathrm{g}$.UV spectrophotometry peak confirms the presence of silver nanoparticle. The extract shows effective antioxidant property with $\mathrm{IC}_{50}$ value $42.32 \mathrm{\mu g} / \mathrm{ml}$ for $\mathrm{DPPH}$ assay and $\mathrm{IC}_{50}$ value $45 \mathrm{\mu g} / \mathrm{ml}$ for FRAP. The Crateva religiosa bark extract could be a novel source of antioxidant.
\end{abstract}

Keywords: Phytochemical, Silver nanoparticle, total phenolic, total flavonoids, UV spectrophotometry, Antioxidant, Scavenging activity.

Introduction

Medicinal plants are useful for various purposes like medicine, dye and perfume, cosmetic and so on. The medicinal plants are not constantly available worldwide. Pharmaceutical companies were in fond of medicinal plants and they derive a drug about one tenth of them [4] [8]. Crateva religiosa possess various medicinal properties. It helps in treating Urinary infection, weight loss, inflammation. It also helps in strengthening the bones and muscles. Also play vital role in curing bladder stones. Also act as an antidote for snake bite. The barks of the plant were used to cure kidney and bladder stones and also for rheumatoid fever, it is prepared as a decoction in ancient days. Helps in treating skin disorders [10].

Phytochemicals are derived from plants and are present in all parts of the plants and also have pharmacological properties. Alkaloids, Flavonoids, Phenols, Terpenoids are some of the important secondary metabolites. Physical, chemical and biological properties of Silver nanoparticle leads to the 
catalytic activity, bactericidal effect and play main role in nano biotechnological research [13],[1]. Nanoscience is a new inter disciplinary subject. It depends on fundamental properties of nanosized objects [14][15].Silver nanoparticles coated papers are used to prevent the microbial growth in food it is covered by a paper that coated with [3]. Also used in hospital to reduce inflammation caused by surgery and also act as wound healing property [2]. Free radicals are naturally produced by human body. The action of free radicals is obstructed by chemicals which are referred as antioxidants. Researchers found person who had longest life span had higher level of antioxidants.

\section{Materials and Methods}

Plant sample:

The barks of Crateva religiosa was collected from Pachalur hills locate in Dindugal district and were authenticated by Botanical Survey of India, Southern Regional Centre, Coimbatore.

Sample Preparation:

Fresh barks of Crateva religiosa was collected washed and shadow dried for 15 days and was made into a fine powder. Into a clean conical flask $5 \mathrm{gm}$ of powder was added and $50 \mathrm{ml}$ of distilled water was poured and kept in a shaker and mixed thoroughly. This maceration process was done in regular intervals. Then the mixture is filtered to obtain a crystal-clear solution.

Phytochemical analysis:

Test for Alkaloids: Few ml of bark extract was taken. Treat it with 4-5 drops of Wagner's reagent. Formation of reddish-brown precipitate indicates the presence of alkaloids.

Test for Flavonoids: $2 \mathrm{ml}$ of extract and few drops of $10 \%$ ferric chloride solution was added and the formation of green or blue colour indicates the presence of flavonoids.

Test for Phenols: $2 \mathrm{ml}$ of extract was taken and 5\% ferric chloride solution was added to it. Appearance of deep blue colour or black colour indicates the presence of phenols.

Test for Tannins: Into a $1 \mathrm{ml}$ of extract $10 \%$ ferric chloride solution was added and the formation of black colour indicates the presence of tannins.

Test for Aminoacids: Few ml of plant extract was taken in a clean test tube. Into that a little a amount of ninhydrin reagent were added. Purple or violet colour formation confirms the presence of aminoacids 
Test for Saponins: $2 \mathrm{ml}$ of bark extract was added into the test tube. $6 \mathrm{ml}$ of water was added into it. The mixture was shaken vigorously. Persistant foam will be formed within few seconds. The formation of foam indicates the presence of saponins.

Test for Phlobatannins: 3ml plant extract and $2 \mathrm{ml}$ of $1 \%$ dilute hydrochloric acid were added into the test tube and boiled. Deposition of red precipitate indicates the presence of phlobatannins.

Test for Steroids: In a fresh test tube $1 \mathrm{ml}$ extract and $2 \mathrm{ml}$ of chloroform was added along with $0.2 \mathrm{ml}$ of concentrated sulphuric acid. Formation of red colour precipitate indicates the presence of steroids.

Total Phenol content:

Folin-Ciocalteu method was used to determine the total phenol content. $10 \mu \mathrm{l}$ of extract was taken. Diluted it with $190 \mu \mathrm{l}$ of distilled water. $2 \mathrm{ml}$ of Folin-Ciocalteu reagent was added to it. $4 \mathrm{ml}$ of $7.5 \% \mathrm{Na} 2$ CO3 solution was added into the mixture after 5 minutes. The mixture was kept in a room temperature for 30 minutes. Absorbance was read at 750nm. Gallic acid was used as a standard. The total phenolic content present in the bark extract was expressed in a form of milligrams of catechol per gram of dry weight [5] [6].

Total Flavonoid content:

Total content of flavonoids was determined by spectrophotometric method. $50 \mu \mathrm{l}$ of bark extract was taken and $4 \mathrm{ml}$ of distilled water was added to it. $0.3 \mathrm{ml}$ of $5 \%$ NaNo3 solution was added along with $0.3 \mathrm{ml}$ of $10 \%$ Aluminium chloride solution. The mixture was incubated for about 5 minutes. $2 \mathrm{ml}$ of 1 $\mathrm{mol} / \mathrm{L}$ Sodium hydroxide solution was added to this mixture. Final volume was made upto 10ml with double distilled water. The mixture was finally kept for 15 minutes. Read the absorbance at 510nm. Here Quercetin was used as standard [12].

Synthesis of silver nanoparticle

$1 \mathrm{ml}$ of pure aqueous bark extract and $9 \mathrm{ml}$ of $1 \mathrm{Mm}$ silver nitrate were added to synthesis silver nanoparticles. Stir the mixture continuously for 30 minutes in a magnetic stirrer. There will be a gradual colour change from light yellow to reddish brown colour to confirms the formation of silver nanoparticles in plant extract. Synthesis of silver nanoparticle is monitored by UV-Visible spectrophotometer LMSPUV1000B LABMAN in the range from $250-800 \mathrm{~nm}$. The peak of wavelength confirms the presence of silver nanoparticle [11].

In vitro Antioxidant activity 
DPPH scavenging activity: Antioxidant activity of aqueous bark extract was determined by 1,1 diphenyl- 2- picryl- hydrazil assay. Into a test tube add $0.5 \mathrm{ml}$ of DPPH and $0.5 \mathrm{ml}$ of methanol in it. This test tube serves as control. Into a clean dry five test tubes the silver nanoparticle synthesized aqueous bark extract was taken in different concentrations as $10 \mu \mathrm{l}, 20 \mu \mathrm{l}, 30 \mu \mathrm{l}, 40 \mu \mathrm{l}, 50 \mu \mathrm{l}$. And the volume of these test tubes were made upto $0.5 \mathrm{ml}$ using methanol. After that added $0.5 \mathrm{ml}$ of DPPH in the test tubes. Incubate all test tubes in a dark for 30 minutes at room temperature. Ascorbic acid was used as standard. The absorbance was read using spectrophotometer at 517nm [9]. Percentage inhibition was calculated by

$\%$ inhibition $=$ Absorbance of control - Absorbance of sample/ Absorbance of control $\times 100$

\section{FRAP Antioxidant Assay}

Antioxidant activity of aqueous bark extract was determined by Ferric Reducing Antioxidant Power assay. $1 \mathrm{ml}$ of FRAP reagent and 1ml of distilled water was taken in a test tube as control. Extracts were taken in clean dry fresh test tubes with different concentrations as $5 \mu \mathrm{l}, 10 \mu \mathrm{l}, 15 \mu \mathrm{l}, 20 \mu \mathrm{l}, 25 \mu \mathrm{l}$. All the test tubes were made up to $1 \mathrm{ml}$ using distilled water and $1 \mathrm{ml}$ of FRAP reagent was added in all tubes. The test tubes were kept in a room temperature for 20 minutes. The absorbance was read at $595 \mathrm{~nm}$ using spectrophotometer [7]. Percentage inhibition was calculated by

$\%$ inhibition $=$ Absorbance of control - Absorbance of sample/ Absorbance of control $\times 100$

Results:

Phytochemical constituents such as alkaloids, flavonoids, phenols, tannins, saponins and steroids were present in Crateva religiosa bark extract.

Table 1. Phytochemical analysis of plant extract

\begin{tabular}{c|c}
\hline Phytochemicals & Aqueous extract \\
\hline Alkaloids & + \\
Flavonoids & + \\
Phenols & + \\
Tannins & + \\
\hline
\end{tabular}




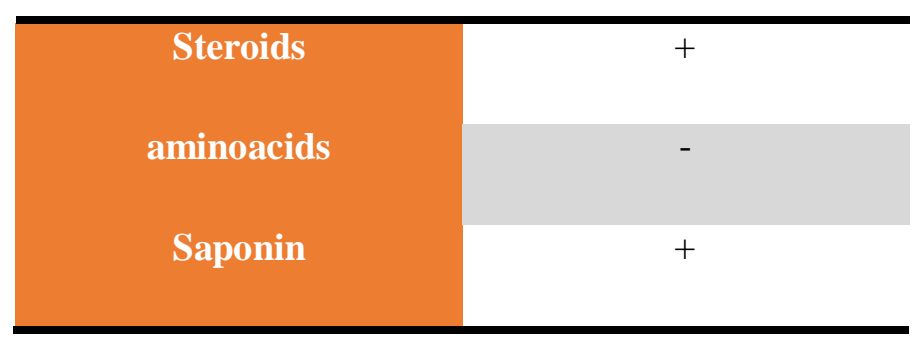

$(+)=$ presence of phytochemicals $(-)=$ absence of phytochemicals

Total phenol content:

Total amount of phenols present in aqueous extract was found to be $1.423 \mathrm{mg}$ GAE/g. The standard gallic acid was found to be $2.00 \mathrm{mg} \mathrm{GAE} / \mathrm{g}$.

Total flavonoid content:

Total amount of flavonoid present in the aqueous extract was found to be $1.6 \mathrm{mg}$ QE/G. The standard was found to be $2.52 \mathrm{mg} / \mathrm{g}$.

Synthesis of silver nanoparticle

The bark extract gradually changes the colour into dark reddish brown colour indicating the presence of silver nanoparticles. The peak wavelength of the bark extract is found between 400$450 \mathrm{~nm}$.

Figure 1: UV - Visible spectroscopy peak wavelength

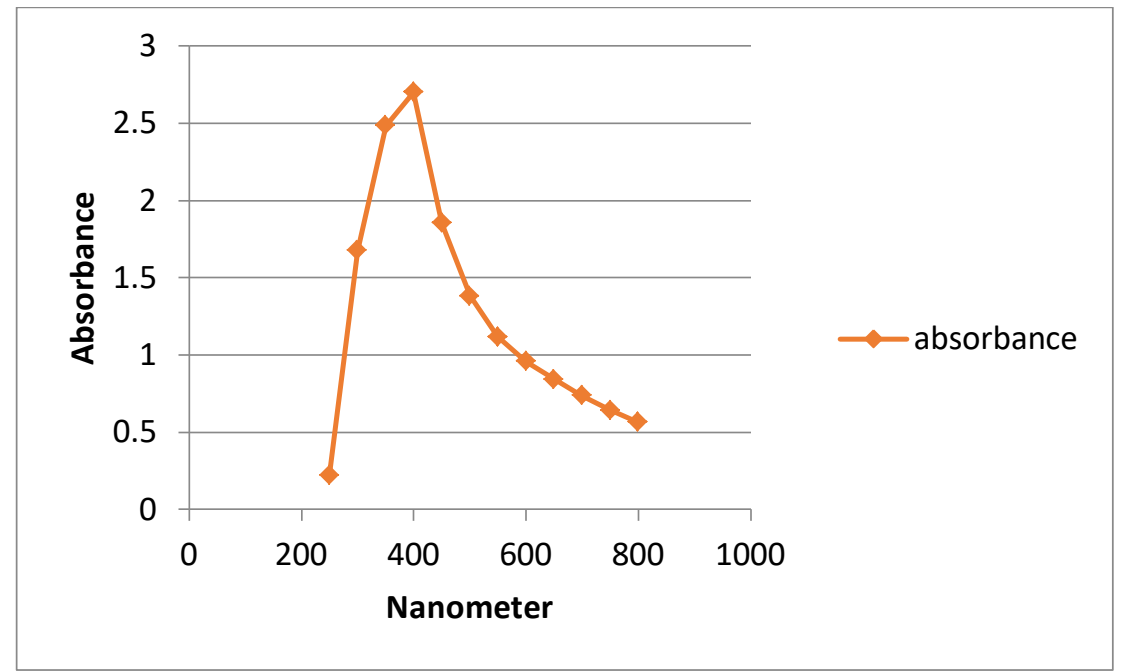


DPPH scavenging activity

The aqueous bark extract shows good antioxidant potential with $94.47 \%$ at concentration of $50 \mu \mathrm{l}$ and the $\mathrm{IC}_{50}$ value of Crateva religiosa was found to be $42.32 \mu \mathrm{g} / \mathrm{ml}$.

Table 2: DPPH activity in silver nanoparticle synthesized aqueous extract

\begin{tabular}{|c|c|c|c|}
\hline $\begin{array}{l}\text { Concentration } \\
\qquad(\mu \mathrm{l})\end{array}$ & Control & $\begin{array}{c}\% \text { Inhibition of } \\
\text { Extract }\end{array}$ & $\begin{array}{l}\text { \% Inhibition of } \\
\text { Standard }\end{array}$ \\
\hline $10 \mu \mathrm{l}$ & 0.0651 & 23.9 & 15 \\
\hline $20 \mu \mathrm{l}$ & 0.0651 & 43.9 & 38 \\
\hline $30 \mu \mathrm{l}$ & 0.0651 & 57.75 & 56 \\
\hline $40 \mu \mathrm{l}$ & 0.0651 & 71.58 & 73 \\
\hline $50 \mu \mathrm{l}$ & 0.0651 & 94.47 & 90.5 \\
\hline
\end{tabular}

Figure 2: Calibration curve of DPPH assay

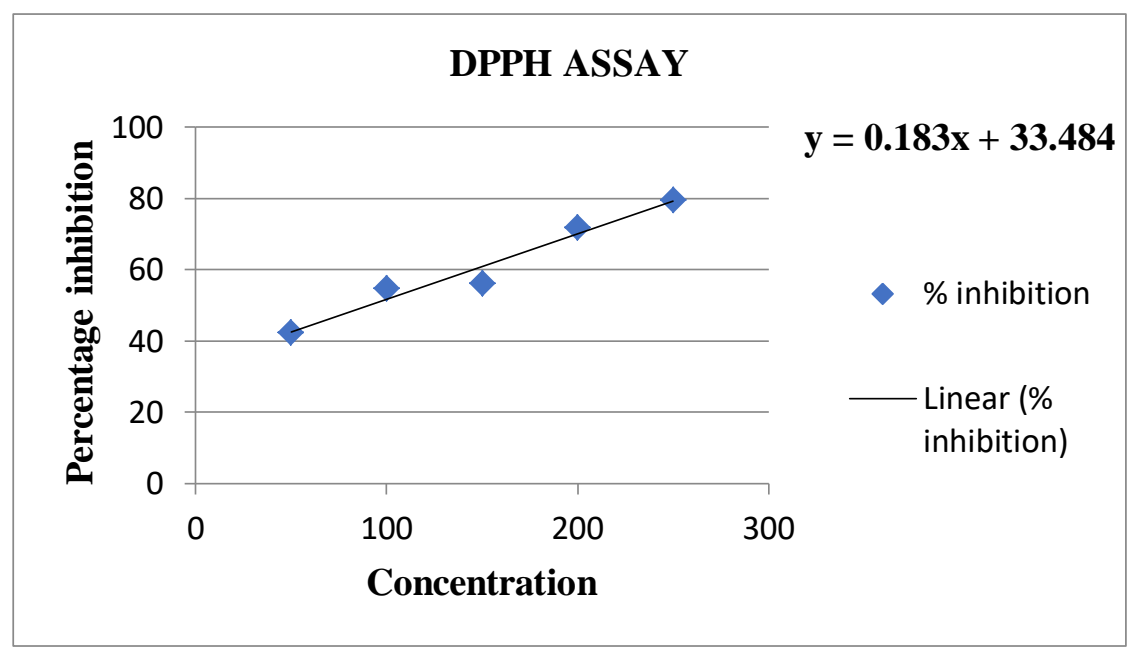


FRAP assay

FRAP assay of Crateva religiosa extract exhibited $89.33 \%$ at concentration of $25 \mu$ l which is higher than the standard inhibition 83\% exhibiting higher antioxidant potential. The $\mathrm{IC}_{50}$ value of Crateva religiosa was found to be $45 \mu \mathrm{g} / \mathrm{ml}$.

Table 3: FRAP activity in silver nanoparticle synthesized aqueous extract

\begin{tabular}{cccc}
\hline $\begin{array}{c}\text { Concentration } \\
(\mu \mathrm{l})\end{array}$ & Control & $\begin{array}{c}\text { \% Inhibition of } \\
\text { Extract }\end{array}$ & $\begin{array}{c}\text { \% Inhibition of } \\
\text { Standard }\end{array}$ \\
\hline $5 \mu \mathrm{l}$ & 0.347 & 29.39 & 33 \\
$10 \mu \mathrm{l}$ & 0.347 & 45.82 & 44 \\
$15 \mu \mathrm{l}$ & 0.347 & 59.94 & 71 \\
$20 \mu \mathrm{l}$ & 0.347 & 76.36 & 83 \\
\hline
\end{tabular}

Figure 3: Calibration curve of FRAP assay 


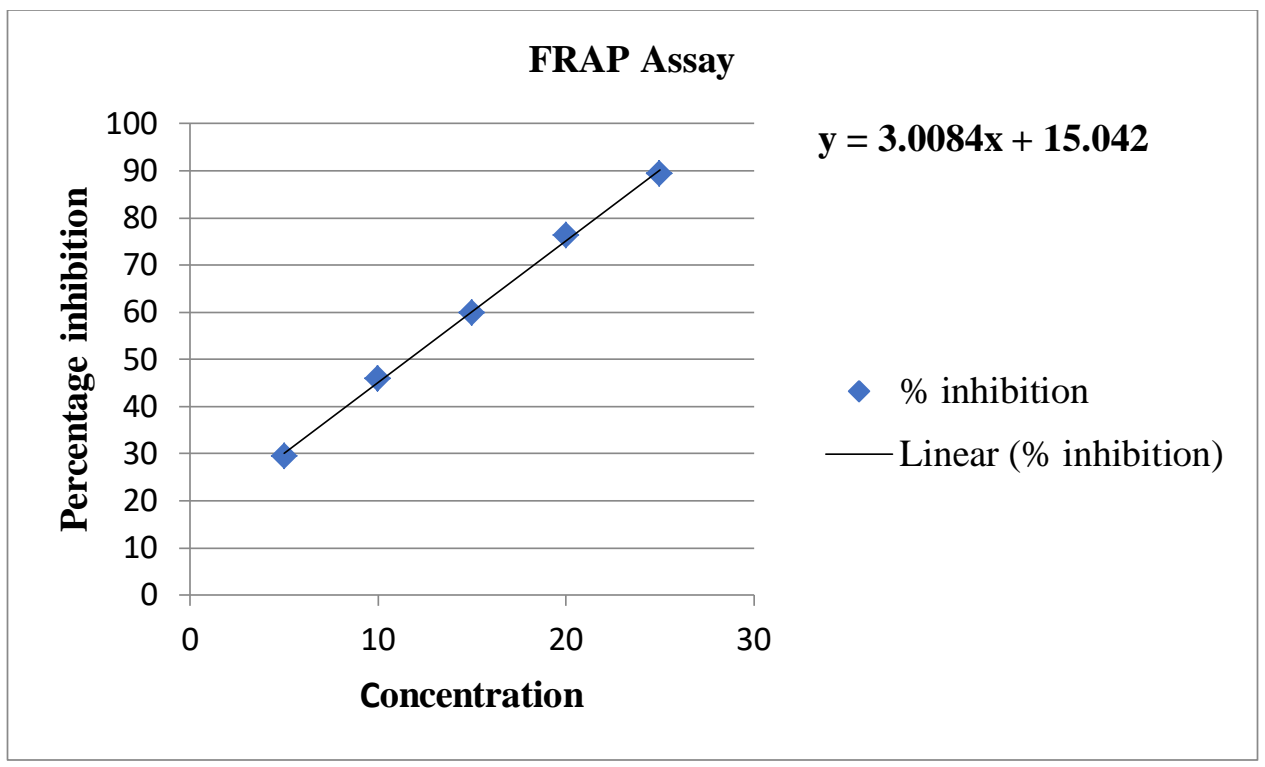

Summary and Conclusion:

The phytochemical analysis of aqueous extract shows presence of phytocontituents such as alkaloids, flavonoids, phenols, tannins, steroids and saponins. The silver nanoparticles were synthesized and antioxidant assays were performed using DPPH and FRAP assay. The results indicating that the barks of Crateva religiosa are rich in antioxidant property. Further study may lead to development of new drug compound to treat damages caused by free radicals.

Acknowledgement:

The authors are grateful to Navarasam Arts and Science College for Women, Arachalur, Erode-63101, Botanical Survey of India, Coimbatore and VJ Biotech, Coimbatore.

Reference:

1. A.M.Fayaz, K.Balaji, M.Girilal, R. Yadav, P.T.Kalaichelvan, and R.Venketesan, "Biogenic synthesis of silver nanoparticles and their synergistic effect with antibiotics: a study against gram positive and gram negative bacteria”, Nanomedicine: Nanotechnology, Biology, and Medicine, vol. 6, no.1, pp. e103-e109,2010.

2. Fong J, Wodd F (2006) Nanocrystalline silver dressing in wound management: a review. Int J Nanomed 1(4):441-449.

3. Gottesmann R, Shukla S, Perkas N, Solovyov LA, Nitzan Y, Gedanken A (2011). Sonochemial coating of paper by microbiocidal silver nanoparticles. Langmuir 27(2): 720-726. Coi: 10.1021/ la $103401 z$. 
4. Huang H. Plant diversity and conservation in China: Planning a strategic bioresource for a sustainable future. Bot J Linn Soc. 2011; 166:282-300.

5. M Madhu, V Sailaja, TNVSS Satyadev, MV Satyanarayana. Quantitative phytochemical analysis of selected medicinal plant species by using various organic solvents. Journal of Pharmacognacy and Phytochemistry 2016; 5(2):25-29.

6. Naima Saeed, Muhammad R Khan, Maria Shabbir. Antioxidant activity, total phenolic and total flavonoid content of whole plant extracts Torilis leptophylla L. BMC Complementary and Alternative medicine,2012; 12:221.

7. Nishaa. S, Vishnupriya. M, Sasikumar. J.M, Hephzibah P Christabel, Gopalakrishnan. V.K. Antioxidant activity of ethanolic extract of Maranta arundinacea. L tuberous rhizomes. Asian Journal of Pharmaceutical and Clinical research. Vol 5,Issue 4, 2012.

8. Rafiean- Kopaei M. Medicinal plants and the human needs. J Herb Med Pharm. 2013; 1:1-2.

9. Rajani Kanta Sahu, Manoranjan Kar, Rasmirani Routray. DPPH Free Radical Scavenging Activity of Some Laefy Vegetables used by Tribals of Odisha, India. Journal of Medicinal Plant Studies. Vol-1, Issue:4, 21-27, 2013.

10. Saptako J., J. of Appl. Biomed., 2003, 1: 7-12.

11. Shakeel Ahamed, Saifullah, Mudasir Ahmed, Babu Lal Swami\& Saiqalkram (2016) Green synthesis of silver nanoparticles using Azadirachta indica aqueous leaf extract, Journal of Radiation Research and Applied Sciences, 9:1,1-7, DOI:10.1016/J.JRRAS.2015.06.006.

12. Sulaiman Mohammed and Fahilah Abd Manan. Analysis of total phenolic, tannins and flavonoids from Moringa oliefera seed extract. Journal of Chemical and Pharmaceutical research.,2015, 7(1): 132-135.

13. V.K. Sharma, R.A. Yngard, and Y.Lin, "Silver nanoparticles: green synthesis and their antimicrobial activities,” Advances in Colloid and Interface Science, vol145, no.1-2, pp.8396,2009.

14. K.M.M. Abou El- Nour, A.Eftaiha,A.Al-Warthan and and R.A.A. Ammar, "Synthesis and applications of silver nanoparticles”, Arabian Journal of Chemistry, vol.3, no.3, pp.135-140, 2010.

15. P. Mohanpuria, N.K. Rana, and S.K. Yadav,”Biosynthesis of nanoparticles: technological concepts of future applications”. Journal of Nanoparticle Research, vol 10, no. 3, pp.507517, 2008. 